\title{
Métastases osseuses de la voûte crânienne
}

\section{Bone metastases of the cranium vault}

\section{F. Renai · C. Granier-Trottin · P. Ray}

Reçu le 27 janvier 2012 ; accepté le 29 février 2012

(C) SFMU et Springer-Verlag France 2012

Un homme de 68 ans consulte pour une aphasie depuis plusieurs heures. Le patient est suivi depuis six ans, pour un adénocarcinome de la prostate, traité par radiothérapie et chimiothérapie avec métastases osseuses aux épaules et au rachis. Le scanner est réalisé dans l'hypothèse de métastases intracérébrales. En réalité, le scanner sans (Fig. 1) et avec injection (Fig. 2) montre de multiples métastases osseuses de la voûte crânienne d'aspect de pseudoméningiome (Fig. 3) (en fenêtre osseuse), réalisant un effet de masse sur le ventricule latéral gauche et un engagement sous-factoriel.

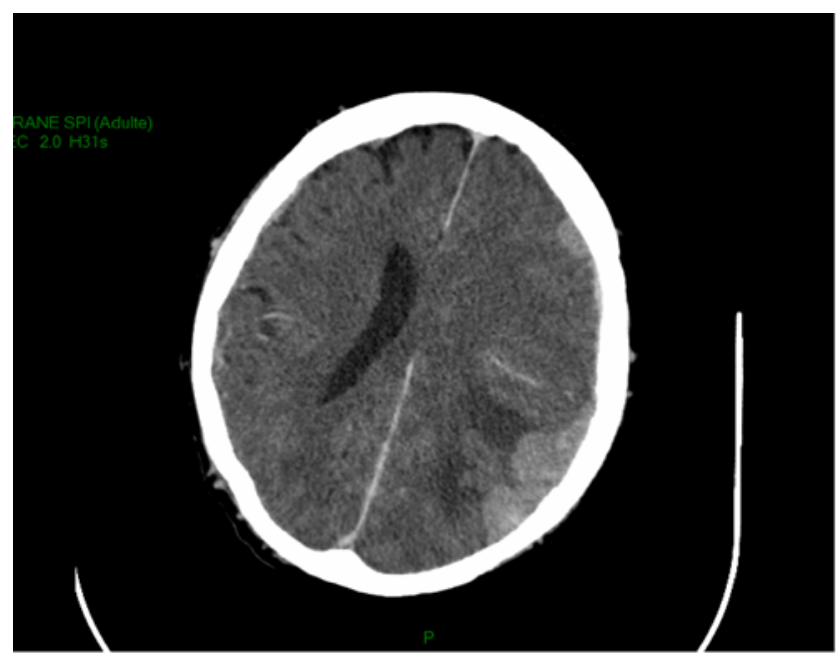

Fig. 2 Scanner avec injection

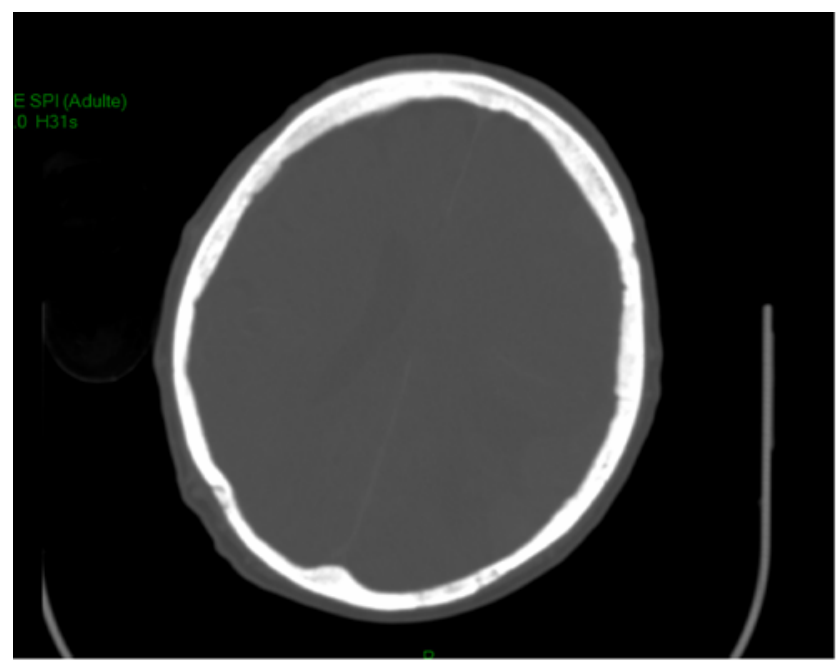

Fig. 3 Scanner en coupes osseuses

F. Renai $\cdot$ C. Granier-Trottin $\cdot$ P. Ray $(\bowtie)$

Service d'accueil des urgences, Hôpital Tenon,

4, rue de la Chine, F-75020 Paris, France

e-mail : patrick.ray@tnn.aphp.fr 